\title{
Outliving colorectal cancer
}

I n Canada in 2007, about 20460 new cases of colorectal cancer will be diagnosed and 8700 people will die from this disease. ${ }^{1}$ About half would live if this country had a more robust and coherent approach to early detection and treatment. Unlike lung cancer, another big killer, colon cancer is easy to detect in its early stage, when it is most often premalignant. And unlike early detection in breast and prostate cancer, early detection in colorectal cancer, especially in the precancerous adenoma stage, routinely leads to excision and cure. Furthermore, if colorectal cancer is detected early, the mortality is low, with $90 \%$ of patients surviving 5 years.

Most lesions are detected in asymptomatic patients screened by manoeuvres such as fecal occult blood testing, sigmoidoscopy or colonoscopy. ${ }^{2}$ A single exposure to sigmoidoscopy reduces the risk of fatal distal colorectal cancer by about $60 \%$ over Io years and reduces the risk of colon cancer by $44 \%$ over 6 years. ${ }^{3}$ In addition, the incremental costeffectiveness ratio for each of the currently accepted modalities for colorectal cancer screening is consistently less than $\$ 50$ ooo per life-year saved - below that for cervical, breast and prostate cancers. ${ }^{4}$

With the anticipated introduction of new diagnostic technologies, such as computed tomography colography, stool DNA testing and wireless videocapsule examination of the colon, patients may, in the future, be able to undergo screening with minimal disruption, perhaps even in their home or workplace. But in the foreseeable future, these methods will not supplant the need for conventional colonoscopy to address true- and false-positive results of colonic pathology by other screening methods. Nor will these new technologies address barriers to screening.

The proportion of patients screened for colorectal cancer has been extraordinarily low in Canada. ${ }^{5}$ In this issue, we highlight the results of a 2003 survey in which only $23.5 \%$ people at average risk reported receiving screening. ${ }^{6}$ By contrast, in the United States in 2000, where a concerted effort was made to introduce national screening, $62.9 \%$ of people at average risk underwent screening. ${ }^{7}$ National screening programs are also under way in the United Kingdom and Europe, but Canada continues to lag, with only a few provincial initiatives (see page 593).

A concerted effort to combat this cancer must begin with the adoption of colorectal screening as a national health priority. Canada's program must include adequate resources as well as patient and physician education. Informing Canadians of the risks of colorectal cancer will likely prompt them to request screening. But physicians have a key role. At present, the most common reason for not undergoing screening is that it was not recommended by the treating physician. (Practitioners should take note that over half of all malpractice actions against primary care physicians with regard to gastrointestinal diseases result from a delay in colorectal cancer diagnosis.)

Until there is an active national program, individual physicians must take the lead. Although several professional societies and foundations are poised and willing to help, physicians must first address their own ignorance and reticence and accept their duty to begin informing and persuading their patients to be screened.

We do have the means and the opportunity to stop this killer. We lack only the education and the national will; it is abundantly clear that to stay the present course of inaction will continue to cost thousands of lives.

\section{Alan Barkun MDCM MSc}

Chairholder, Douglas G. Kinnear Chair

in Gastroenterology

Director, Division of Gastroenterology

McGill University and McGill University Health Centre

Montréal, Que.

Ken Flegel MDCM MSc

Senior Associate Editor, CMAJ

With the Editorial-Writing Team (Paul C. Hébert MD MHSc, Matthew Stanbrook MD PhD, Barbara Sibbald BJ, Noni MacDonald MD MSc and Amir Attaran LLB PhD)

\section{REFERENCES}

I. Canadian cancer statistics 2007. Toronto: Canadian Cancer Society/National Cancer Institute of Canada; 2007. p. I3. Available: http://I29.33.I70.32/ccs/internet /standard/o,3182,3172_I4279__langId-en,oo.html (accessed 2007 Aug 2).

2. Ferraris R, Senore C, Fracchia M, et al. Predictive value of rectal bleeding for distal colonic neoplastic lesions in a screened population. Eur J Cancer 2004;40:245-52.

3. Muller AD, Sonnenberg A. Prevention of colorectal cancer by flexible endoscopy and polypectomy: a case-control study of 32702 veterans. Ann Intern Med I995; I23:904-IO.

4. Barkun AN, Jobin G, Cousineau G, et al. The Quebec Association of Gastroenterology position paper on colorectal cancer screening-2003. Can J Gastroenterol 2004;I8:509-I9.

5. Rabeneck L, Paszat LF. A population-based estimate of the extent of colorectal cancer screening in Ontario. Am J Gastroenterol 2004;99:II4I-4.

6. Zarychanski R, Chen $\mathrm{Y}$, Bernstein $\mathrm{CN}$, et al. Frequency of colorectal cancer screening and the impact of family physicians on screening behaviour. CMAJ 2007; I77:593-7.

7. Peterson NB, Murff HJ, Ness RM, et al. Colorectal cancer screening among men and women in the United States. J Womens Health (Larchmt) 2007;16:57-65. 